\title{
Animation-Based Teaching of Semiconductor Devices: Long-Term Improvement in Students' Achievements in a Two-Year College
}

\author{
http://dx.doi.org/10.3991/ijep.v5i1.4182 \\ A. Gero ${ }^{1}$ and W. Zoabi ${ }^{2}$ \\ ${ }^{1}$ Technion - Israel Institute of Technology, Haifa, Israel \\ ${ }^{2}$ ORT Braude College, Karmiel, Israel
}

\begin{abstract}
The structure and operating principle of semiconductor devices are a central topic in teaching electronics, both in universities and in two-year colleges. Teachers teaching this subject normally run into substantial difficulties stemming from the fact that a major part of the concepts and processes that are relevant to understanding these devices are abstract. In light of the advantages of multimedia in illustrating dynamic processes, the chapter covering the field effect transistor (FET) has recently been taught through animation at a two-year college in Israel. The study presented here has examined, through quantitative tools, whether animation-based teaching of the FET had any effect on students' achievements in the subject of basic electronic devices. Forty electronics students have participated in the study. Its findings indicate that in the short and long term alike, the achievements of students who studied the transistor through animation were significantly higher than those of their peers who studied it through a traditional method. Additionally, the effect size was very large.
\end{abstract}

Index Terms-Animation-based learning, electronic devices, long-term effect, two-year colleges

\section{INTRODUCTION}

The structure and principle of operation of semiconductor devices are one of the basic topics in electrical engineering. This subject is taught, at varying levels, both in universities and in two-year colleges. Transistors ${ }^{1}$ are a central part of the curriculum, in light of their importance as basic devices in the different areas of electronics analog and digital alike. However, in order to understand the operating principle of these electronic devices, the students are in need of broad knowledge in physics - a situation which poses a real challenge to teachers [1]. Further, some of the relevant concepts and processes such as holes, depletion region, drift and diffusion are particularly difficult to understand, as they are abstract [2].

As a possible solution to the above difficulty, teachers and researchers have developed animations illustrating central processes occurring in electronic devices. As in other areas of electrical engineering where educational animations have been developed - such as electromag-

\footnotetext{
${ }^{1}$ A transistor is a basic electronic device used as an amplifier or switch. There are different types of transistors. The most important of them are the bipolar junction transistor (BJT), which is relatively complex, and the field effect transistor (FET), which is relatively simple.
}

netism [3], electro-optics and acousto-optics [4] and power electronics [5] - the basis for such development has been the intention to utilize the advantages of animation in cases where processes are difficult to demonstrate in the classroom or even the traditional laboratory [6]. It should be noted, however, that remote control and virtual laboratory practices enable students to visualize abstract concepts and as a result their understanding is enhanced [7][9]. The vast majority of animations covering electronic devices are intended for university students [10]-[13] and a minority for two-year college students [2]. Thus, for example, Lundgren \& Jonsson [10] have developed an animation describing drift and diffusion processes in semiconductors and found a considerable improvement in students' level of interest, but not in their degree of understanding. In comparison, Sihar et al. [11] and Gero et al. [2] found improvement in the achievements of students who had studied electronic devices through animation. These results contribute to the continuing debate - so far remaining unsettled - on whether the use of computer animation is preferable to traditional teaching methods [14]-[15].

It is important to note that reading the extensive literature covering the above issue reveals that the number of educational studies examining the long-term effect of animation-based learning is quite small [16]. One study examining the long-term effect of educational animation has shown that over a period of one year, the academic achievements of students who studied the subject of the bipolar junction transistor (BJT) through animation remained significantly higher than those of their peers who studied through a traditional method [17].

The current study focused on a device from the second family of transistors - the field effect transistor (FET) examining whether animation-based learning of the FET a simpler device than the BJT - has an effect on students' achievements over varying time periods.

The paper begins with a concise review of long-term effects of learning in general, and specifically in the context of animation. Then, the goal of the study and its methodology are presented. Finally, the findings are discussed.

\section{THEORETICAL BACKGROUND}

It is customary to define "retention" as the ability to remember information or skills formerly learned at a later point in time [18]. From this very definition becomes 
apparent the great importance of retention in education at large [19] and particularly in engineering education [20] where one of the basic assumptions is that knowledge and skills attained at a given point should serve the student on later stages of learning as well.

Studies on retention can be classified into three groups: laboratory experiments, educational studies and naturalistic studies [16]. Laboratory studies, beginning with the famous work of Ebbinghaus [21], examine retention under controlled laboratory conditions over a characteristic time period of hours or several days. In comparison, in naturalistic studies occurring in the natural environment, such period can be several years. Educational studies occurring in the classroom - the kind on which we will focus below - examine retention over a period of several months. Studies in this category have examined retention in a variety of areas of learning such as psychology [22], chemistry [23] and medical sciences [24]-[25]. The results of most of these studies can be explained through the Ebbinghaus curve according to which the rate of loss of knowledge is relatively high at the end of the learning process and becomes more moderate later.

In light of the importance of promoting retention among students, researchers suggest a variety of means to assist retention. Ausubel [26], for example, recommends the use of "advance organizers" - cognitive tools connecting new knowledge to knowledge learned earlier. Others claim that retention can be improved by learning through nontraditional methods [27]. Among these methods are project-based learning [28], problem-based learning [29] or the use of educational technology [30]. Dori et al. [31] even propose combining several methods, such as using educational technology in an active learning environment.

As mentioned at the beginning of this paper, the number of studies examining the long-term effects of animation-based learning is quite small. These studies indicate, among other things, a significant improvement in the retention ability of engineering students studying a course in electromagnetism in an active learning environment including multimedia [31], and a significant gap between the achievements of students in a two-year college who studied the BJT through animation and those of students who studied it through a traditional method. This gap, in favor of the first group, was maintained for a year after the learning process had ended [17].

The positive effect of animation can be explained in light of the dynamic hypothesis claim [32] based on the cognitive theory of multimedia learning [33]. According to it, by animation illustrating motion, it reduces the students' cognitive load - a load stemming from the need to construct a dynamic image necessary in order to understand the process being learned. Therefore, animation promotes better learning that is also reflected in improved retention ability.

As a balance, the opposite hypothesis should also be mentioned, i.e., the static hypothesis [34] claiming that actually static means, such as a written text and diagrams are those leading to better learning. According to the supporters of the static hypothesis, since static means only present the key stages of the process being learned, the student can focus on the most important information thus reducing his/her cognitive load. As covered above, unambiguous findings supporting this approach or the other have yet to be attained [14]-[15].

\section{GOAL AND METHODOLOGY}

The aim of this study was to examine whether animation-based learning of the FET had an effect on students' achievements in the short and long term. Forty students of electronics in a two-year college in Israel took part in the study. The electronics program focuses on the practical aspect rather than theory, and trains students who are relatively low achievers and who attain technical jobs in industry after graduating.

The students attended a basic course on electronic devices. The course covered the following devices: the diode, FET (JFET and MOSFET), BJT and amplifiers. At the end of the course students are expected to be able to solve problems involving the structure and operating principle of these devices, modes of operation, operating point analysis and small signal equivalent circuits.

At the beginning of the course the students studied the diode together in one classroom by using static diagrams drawn on the board. When learning was completed, students were randomly assigned into two equal-sized groups - an experimental group and control group. The members of each group were tested by an identical achievement test on the subject of the diode (Test 0). Later, the experimental group studied the structure and operating principle of the FET for eight hours through animation presented by the teacher.

The animation had been developed by the Multimedia Group of the Department of Engineering at the University of Cambridge [35]. This animation had been selected out of many animations available in databases, being relatively simple and not requiring any advanced knowledge of physics that had not been attained by the students, such as Fermi levels. Another consideration for its selection had been its development in light of design principles [36] intended to enhance meaningful learning. Thus, for example, a relevant text is shown in proximity to the animation (spatial contiguity principle). Additionally, the animation refrains from excessive use of text or images that may divert the student's attention off the main issue (coherence principle). The teacher accompanied the animation with his explanations, brought the important points to the students' attention, and emphasized the animation's limitations in order to prevent the development of misconceptions among the students [37].

The control group was taught the same subject by the same teacher and for the same number of hours, through static diagrams drawn on the board. It should be noted that the diagrams represented central points of the processes occurring in the device and were as similar as possible to the ones shown in the animation. Additionally, the explanations provided by the teacher to both groups had been prepared in advance and were therefore as similar as possible.

At the end of this period, both groups were tested by an identical achievement test on the structure and operating principle of the FET (Test 1). Later, the separation between the groups was cancelled, and their members studied together in one classroom the remaining contents of the course, as mentioned above, through static diagrams. It should be emphasized that these contents are based on the contents studied on the first part of the course. At the end of the course, ten weeks after Test 1, the students were tested by an achievement test on all of the course contents, including those tested earlier (Test 2). 
Each of the three tests was validated by two experts in electrical engineering education. To ensure objectivity, each test was graded with a rubric. Additionally, the tests did not contain the student's name but only his/her ID, and were graded in random order after mixing members of the experimental group with the control group, to ensure the person grading them would not be aware of the group to which each test belonged. Selected questions out of the various tests are provided in the Appendix.

\section{FINDINGS}

Table I shows the score (out of 100 points) obtained on the three achievement tests and the corresponding $p$ values obtained on t tests (a higher-powered analysis is ANCOVA, with the scores of Test 0 as a covariant; however, due to the inequality of variances, this type of analysis could not be done in this case). In reading the table it can be seen no significant difference was obtained between the experimental group and control group prior to studying the FET (Test 0 ), but after studying it (Test 1 ) the mean score in the experimental group was significantly higher than the control group. A significant difference was observed at the end of the course as well (Test 2).

Table II shows the effect size for each test, and indicates very high effect size values after the intervention although they reduced with time.

\section{DISCUSSION}

The study indicates a significant gap between the achievements of students who studied the FET through animation and the achievements of their peers who used static diagrams. This significant gap, in favor of the first group, was reflected in the results of Test 1 focusing on the FET itself and Test 2 covering all of the subjects learned on the course and taken ten weeks after Test 1. The effect size can be seen to have reduced with time, which can be assigned to the curve suggested by Ebbinghaus [21]. The above difference supports the claim of the dynamic hypothesis [32] as mentioned in the theoretical background.

These findings are in line with the results of other studies [30]-[31] showing that the use of educational technology at large and particularly multimedia promotes retention. It is interesting to compare the findings of the current study to those described in [17] examining the long-term effect of animation-based learning of the BJT, a more complex device than the FET. In both cases, a significant gap was found between the achievements of two-year college students who had studied the device with the aid of animation and those of their peers who had studied it with static diagrams. In both cases, the gap was accompanied by a very large effect size, and the effect size gradually diminished with time. Although both studies examined retention over different time periods (a year in the case of the BJT compared to ten weeks in the case of the FET), their findings indicate an advantage in the use of animation in teaching simple or complex electronic devices in a two-year college. This can be explained by the fact that dynamic processes that are quite complex occur even in a relatively simple electronic device, making the student's understanding more difficult [1]. As covered above, animation can illustrate these processes and so reduce the student's cognitive load, permitting better learning [32].
TABLE I.

ACHIEVEMENT TESTS: SCORES

\begin{tabular}{|c|l|c|c|c|c|}
\hline Test & \multicolumn{1}{|c|}{ Group } & Mean & SD & t & p-value \\
\hline \multirow{2}{*}{ Test 0 } & Experiment & 79.90 & 22.32 & \multirow{2}{*}{0.61} & n.s. \\
\cline { 2 - 4 } & Control & 83.70 & 15.28 & & \\
\hline \multirow{2}{*}{ Test 1 } & Experiment & 85.50 & 11.39 & \multirow{2}{*}{3.85} & $<0.001$ \\
\cline { 2 - 4 } & Control & 60.90 & 25.45 & & \\
\hline \multirow{2}{*}{ Test 2 } & Experiment & 83.45 & 11.08 & \multirow{2}{*}{3.06} & $<0.01$ \\
\cline { 2 - 5 } & Control & 66.75 & 21.77 & & \\
\hline
\end{tabular}

TABLE II.

ACHIEVEMENT TESTS: EFFECT SIZE

\begin{tabular}{|c|c|}
\hline Test & Cohen's $\boldsymbol{d}$ \\
\hline Test 1 & 1.25 \\
\hline Test 2 & 0.97 \\
\hline
\end{tabular}

The study has several limitations as specified below. Possibly, the teacher's quality of teaching and his expectations of his students were affected by an unconscious bias in favor of the experimental group [38]; it is also possible that the students in the experimental group were more interested in the subject being learned in comparison to their peers as a result of the novelty effect [39]; and finally, the study was based on a relatively small sample. However, we believe that the large, consistent gap obtained cannot only be assigned to these effects.

In spite of the above limitations, the study has significant strengths that reinforce its internal validity: the participants were randomly divided into an experimental group and control group, who studied the same contents over the same number of hours with the same teacher who was meticulous about ensuring the only difference between the groups would amount to the teaching method (animation or static diagrams).

The study's contribution is reflected in showing, for the first time as far as the authors are aware, that animationbased learning of the FET has a long-term effect on academic achievements. The authors believe that this contribution is significant in light of the scarce of literature covering the long-term effect of animation- based learning at large and particularly in the subject of semiconductor devices [16].

\section{SUMMARY}

The study examined whether animation-based learning in the subject of the FET had a short-term and long-term effect on academic achievements. Its findings indicate a significant gap between the achievements of students in a two-year college who studied the FET through animation and those of their counterparts who studied it with static diagrams. The difference, in favor of the first group, was maintained over ten weeks, accompanied by a very large effect size. The size of the effect gradually diminished with time. The current study's findings combined with results of similar studies indicate an advantage of computer animation over traditional methods used in teaching electronic devices. 


\section{APPENDIX}

Following are selected questions excerpted from the different achievement tests.

\section{A. $\quad$ Test 0}

Consider the following circuit (Fig. 1). Assume the diodes are ideal.

1. If switch $\mathrm{S}$ is in position 1:

- Determine the state of each of the diodes in the circuit (active / cut off).

- Calculate the current in the circuit.

2. If switch $\mathrm{S}$ is in position 2 :

- Determine the state of each of the diodes in the circuit (active / cut off).

- Calculate the current in the circuit.

\section{B. Test 1}

Consider the following circuit (Fig. 2).

$\mathrm{V}_{\mathrm{P}}=-6 \mathrm{~V}, \mathrm{I}_{\mathrm{DSS}}=12 \mathrm{~mA}$.

Determine the operating point of the transistor $\left(\mathrm{I}_{\mathrm{D}}, \mathrm{V}_{\mathrm{GS}}\right.$, $\mathrm{V}_{\mathrm{DS}}$ ).

\section{Test 2}

Consider the following circuit (Fig. 3).

$\mathrm{V}_{\mathrm{P}}=-3 \mathrm{~V}, \mathrm{I}_{\mathrm{DSS}}=10 \mathrm{~mA}, \mathrm{r}_{\mathrm{d}}=\infty$.

All capacitors have negligible reactance at the input signal frequency.

1. Determine $R_{S}$ and $R_{D}$ so that the operating point is $\mathrm{I}_{\mathrm{D}}=3 \mathrm{~mA}, \mathrm{~V}_{\mathrm{DS}}=10 \mathrm{~V}$.

2. Draw a small signal equivalent circuit.

3. Calculate the voltage amplification, $A_{V}=V_{o} / V_{i}$.

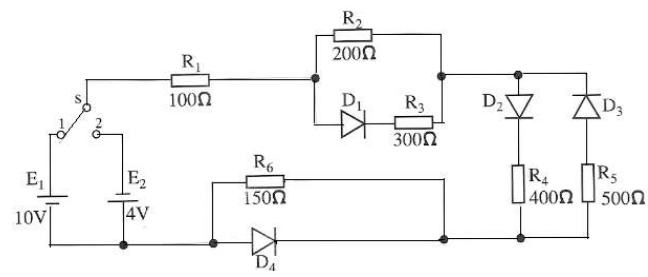

Figure 1. Sample question (Test 0 )

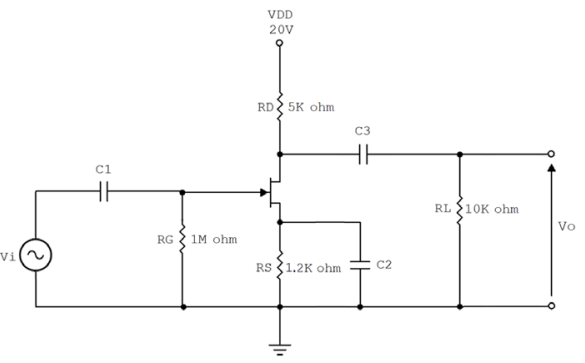

Figure 2. Sample question (Test 1)

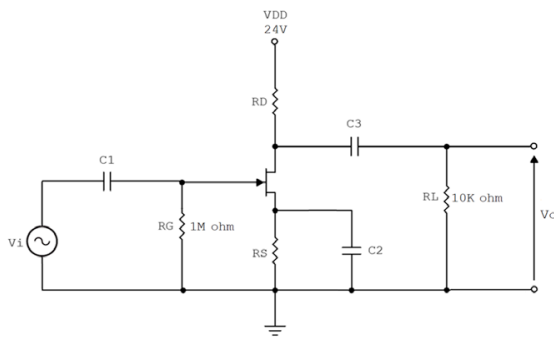

Figure 3. Sample question (Test 2)

\section{REFERENCES}

[1] J. K. Karmalkar, "Simple unified elucidations of some semiconductor device phenomena," IEEE Transactions on Education, vol. 42(4), pp. 323-327, 1999. http://ieeexplore.ieee.org/xpl/articleDe tails.jsp?arnumber=804539 http://dx.doi.org/10.1109/13.804539

[2] A. Gero, W. Zoabi, and N. Sabag, "Animation based learning of electronic devices," Advances in Engineering Education, vol. 4(1), pp. 1-21, 2014. http://advances.asee.org/?publication=animationbased-learning-of-electronic-devices

[3] M. Chetty, S. Hu, and J. Bennett, "An interactive Java-based educational module in electromagnetics," International Journal of Electrical Engineering Education, vol. 40(1), pp. 79-90, 2003. http://manchester.metapress.com/content/1573k29mw024331u/ http://dx.doi.org/10.7227/IJEEE.40.1.9

[4] P. Martínez-Jiménez, M. Varo-Martínez, G. P. Perez, M. C. Martínez, M. Bellido, M. J. A. Ureña, and J. Fernández-Sánchez, "Tutorial and simulation electrooptic and acoustooptic software as innovative methodology to improve the quality of electronic and computer engineering formation," IEEE Transactions on Education, vol. 49(2), pp. 302-308, 2006. http://ieeexplore.ieee.org/ xpl/articleDetails.jsp?arnumber $=1629227$

[5] P. Bauer, J. Dudak, D. Maga, and V. Hajek, "Distance practical education for power electronics," International Journal of Engineering Education, vol. 23(6), pp. 1210-1218, 2007. http://www.ijee.ie/latestissues/Vol23-6/s18 ijee1917.pdf

[6] S. A. Flemming, G. R. Hart, and P. B. Savage, "Molecular orbital animations for organic chemistry," Journal of Chemical Education, vol. 77(6), pp. 790-793, 2000. http://pubs.acs.org/doi/abs/ 10.1021/ed077p790

[7] T. Karakasidis, "Virtual and remote labs in higher education distance learning of physical and engineering sciences," Presented at The Global Engineering Education Conference, 2013. http://ieeexplore.ieee.org/xpl/articleDetails.jsp?arnumber=653019

[8] C. E. Pereira, S. Paladini, F. M. Schaf, "Control and automation engineering education: Combining physical, remote and virtual labs," Presented at the 9th International Multi-Conference on Systems, Signals and Devices, 2012. http://ieeexplore.ieee.org/xpl/ articleDetails.jsp?arnumber $=6197908$

[9] F. Alam, R. G. Hadgraft, and A. Subic,"Technology-enhanced laboratory experiments in learning and teaching," in F. Alam Ed., Using Technology Tools to Innovate Assessment, Reporting, and Teaching Practices in Engineering Education, IGI Global, 2014, pp. 289-302.

[10] P. Lundgren and L. E. Jonsson, "Interactive animations as a tool for conceptualization: An example from semiconductor devices," International Journal of Engineering Education, Interactive Papers, 2005. http://www.ijee.ie/OnlinePapers/Interactive/Lundgren/ Lundgren $04 . \overline{\mathrm{htm}}$

[11] S. Sihar, S. Hj Ab Aziz, and Z. A. Sulaiman, "Design and development of semiconductor courseware for undergraduate students," Journal of Applied Sciences, vol. 11(5), pp. 883-337, 2011. http://perweb.firat.edu.tr/personel/yayinlar/fua 35/35 6586 8.pdf, http://dx.doi.org/10.3923/jas.2011.883.887

[12] C. J. Chang-Hasnain, J. D. Plummer, R. W. Dutton, and Z. Yu, "Development of animated simulation of semiconductor electronic devices for classroom demonstration," 1994. http://wwwtcad.stanford.edu/tcad/education/anim.html

[13] A. Chvála, D. Donoval, J. Marek, P. Príbytný, and M. Molnár, "Education of electronic devices supported by 3-D simulations, Presented at the 9th European Workshop of Microelectronics Education, 2012.

[14] B. Tversky, J. Bauer-Morrison, and M. Betrancourt, "Animation: Can it facilitate?" International Journal of Human-Computer Studies, vol. 57(4), pp. 247-262, 2002. http://www.sciencedirect.com/science/article/pii/S1071581902910 177 http://dx.doi.org/10.1006/ijhc.2002.1017

[15] M. Hegarty, S. Kriz, and C. Cate, "The roles of mental animations and external animations in understanding mechanical systems," Cognition and Instruction, vol. 21(4), pp. 325-360, 2003. http://www.tandfonline.com/doi/abs/10.1207/s1532690xci2104 1 \#.U99vxuOSwSk http://dx.doi.org/10.1207/s1532690xci2104 1 
[16] E. J. Custers, "Long-term retention of basic science knowledge: A review study," Advances in Health Sciences Education, vol. 15(1), pp. 109-128, 2010. http://link.springer.com/article/10.1007/ s10459-008-9101-y http://dx.doi.org/10.1007/s10459-008-9101-y

[17] A. Gero and W. Zoabi, "Computer animation and academic achievements: Longitudinal study in electronics education," International Journal of Engineering Education, vol. 30(5), pp. 12951302, 2014. http://www.ijee.ie/latestissues/Vo15/22 _ijee2908 ns.pdf

[18] G. B. Semb, J. A. Ellis, and J. Araujo, "Long-term memory for knowledge learned in school," Journal of Educational Psychology, vol. 85(2), pp. 305-316, 1993. http://psycnet.apa.org/journals/ edu/85/2/305/ http://dx.doi.org/10.1037/0022-0663.85.2.305

[19] D. F. Halpern and M. D. Hakel, "Applying the science of learning to the university and beyond: Teaching for long-term retention and transfer," Change, vol. 35(4), pp. 36-41, 2003. http://www.tandfonline.com/doi/abs/10.1080/00091380309604109 \#.U99z6OOSwSk http://dx.doi.org/10.1080/00091380309604109

[20] S. St. Clair, "Assessment of the long-term effects of technology use in the engineering classroom on learning and knowledge retention," Ph.D. dissertation, Georgia Institute of Technology, 2004.

[21] H. Ebbinghaus, Ueber das Gedaechnis. Untersuchungen zur Experimentellen Psychologie. Bonset, 1885.

[22] H. C. Rickard, R. Rogers, N. R. Ellis, and W. B. Beidleman, "Some retention, but not enough," Teaching of Psychology, vol. 15(3), pp. 151-152, 1988. http://top.sagepub.com/content/ 15/3/151.short, http://dx.doi.org/10.1207/s15328023top1503_14

[23] H. J. Arzi, R. Ben-Zvi and U. Ganiel, "Forgetting versus savings: The many facets of long-term retention," Science Education, vol. 70(2), pp. 171-188, 1986. http://onlinelibrary.wiley.com/doi/ 10.1002/sce.3730700211/abstract, http://dx.doi.org/10.1002/sce.37 30700211

[24] R. Rodriguez, E. Campos-Sepulveda, H. Vidrio, E. Contreras, and F. Valenzuela, "Evaluating knowledge retention of third-year medical students taught with an innovative pharmacology program," Academic Medicine, vol. 77(6), pp. 574-577, 2002. http://journals.lww.com/academicmedicine/Abstract/2002/06000/ Evaluating Knowledge Retention of Third year.18.aspx http://dx.doi.org/10.1097/00001888-200206000-00018

[25] S. Herzig, R. M. Linke, B. Marxen, U. Börner, and W. Antepohl, "Long-term follow up of factual knowledge after a single, randomised problem-based learning course," BMC Medical Education, vol. 3(3), 2003. http://www.biomedcentral.com/1472-6920/3/3

[26] D. P. Ausubel, The Acquisition and Retention of Knowledge. Kluwer Academic Publishers, 2000.

[27] J. B. Biggs, Teaching for Quality Learning at University. St. Edmundsbury Press, 1999.

[28] S. Waks and N. Sabag, "Technology project learning vs. lab experimentation," Journal of Science Education and Technology, vol. 13(3), pp. 333-342, 2004. http://link.springer.com/article/ 10.1023/B:JOST.0000045460.06506.43, http://dx.doi.org/10.1023/ B:JOST.0000045460.06506.43

[29] D. L. Silverstein and J. R. Baker, "Improving retention of calculus by engineering students in small programs," Presented at the 2003 American Society for Engineering Education Annual Conference \& Exposition, 2003.

[30] Z. Yildirim, M. Y. Ozden, and M. Aksu, "Comparison of hypermedia learning and traditional instruction on knowledge acquisition and retention," Journal of Educational Research, vol. 94(4), pp. 207 214, 2001. http://www.tandfonline.com/doi/abs/10.1080/ 00220670109598754\#.U995IeOSwSk, http://dx.doi.org/10.1080/ 00220670109598754
[31] J. Dori, E. Hult, L. Breslow, and J. W. Belcher, "How much have they retained? Making unseen concepts seen in a freshman electromagnetism course at MIT," Journal of Science Education and Technology, vol. 16(4), pp. 299-323, 2007. http://link.springer.com/article/10.1007\%2Fs10956-007-9051-9 http://dx.doi.org/10.1007/s10956-007-9051-9

[32] L. P. Rieber, "Supporting discovery-based learning within simulations," in R. Z. Zheng. Ed., Cognitive Effects of Multimedia Learning, Information Science Reference, 2009, pp. 217-236.

[33] R. E. Mayer, "Cognitive theory of multimedia learning," in R. E. Mayer Ed., Cambridge Handbook of Multimedia Learning, Cambridge University Press, 2005, pp. 31-48. http://dx.doi.org/10.1017/CBO9780511816819.004

[34] R. E. Mayer, M. Hegarty, S. Mayer, and J. Campbell, "When static media promote active learning: annotated illustrations versus narrated animations in multimedia instruction," Journal of Experimental Psychology: Applied, vol. 11(4), pp. 256-265, 2005. http://psycnet.apa.org/journals/xap/11/4/256/ http://dx.doi.org/10.1037/1076-898X.11.4.256

[35] CUED Multimedia Group, Interactive explanations for semiconductor devices, 2003. http://www-g.eng.cam.ac.uk/mmg/ teaching/linearcircuits/

[36] R. E. Mayer and R. Moreno, "Animation as an aid to multimedia learning," Educational Psychology Review, vol. 14(1), pp. 87-99, 2002. http://link.springer.com/article/10.1023/A:1013184611077 http://dx.doi.org/10.1023/A:1013184611077

[37] H. Yarden and A. Yarden, "Studying biotechnological methods using animations: The teacher's role," Journal of Science Education and Technology, vol. 20(6), pp. 689-702, 2010. http://link.springer.com/article/10.1007/s10956-010-9262-3 http://dx.doi.org/10.1007/s10956-010-9262-3

[38] R. Rosenthal, Experimenter Effects in Behavioral Research. Appleton-Century-Crofts, 1966.

[39] R. E. Clark, "Reconsidering research on learning from media," Review of Educational Research, vol. 53(4), pp. 445-459, 1983. http://rer.sagepub.com/content/53/4/445.short http://dx.doi.org/10.3102/00346543053004445

\section{AUTHORS}

A. Gero holds a B.A. in physics, a B.Sc. in electrical engineering, an M.Sc. in electrical engineering, and a Ph.D. in theoretical physics, all from the Technion - Israel Institute of Technology. In addition, he has an MBA from the University of Haifa, Israel. He is a faculty member at the Department of Education in Technology and Science of the Technion (e-mail: gero@technion.ac.il). His research focuses on electrical engineering education and interdisciplinary education that combines physics with electronics, such as electro-optics and microelectronics education.

W. Zoabi received a B.Sc. in Technology and Science Education in 2008 and an M.Sc. in Technology and Science Education in 2012, from the Technion - Israel Institute of Technology. She is a lecturer at the Department of Electronics and Electrical Engineering of Ort Braude College, Israel (e-mail: wishah@braude.ac.il). Her research focuses on animation-based learning of electronic devices.

Submitted, 29 September 2014. Published as resubmitted by the authors 14 February 2015. 